\title{
A pathological Late Cretaceous carcharodontosaurid tooth from Minas Gerais, Brazil
}

\author{
CARlos Roberto A. CANDEIRO \& DARREN H. TANKE
}

\begin{abstract}
A theropod (Carcharodontosauridae) tooth exhibiting a split carina is the first recorded from upper Maastrichtian Marília Formation (Serra da Galga Member), Minas Gerais State, Brazil. The distal split carina has a distinct Y-shape. Split carinae have been reported elsewhere in Laurasian theropods (tyrannosaurids and allosaurids). - Key words: Cretaceous, Maastrichtian, Carcharodontosauridae, split carinae, tooth, pathology, Peirópolis, Brazil.
\end{abstract}

CAndeIRO, C.R.A. \& TANKE, D.H. 2008. A pathological Late Cretaceous carcharodontosaurid tooth from Minas Gerais, Brazil. Bulletin of Geosciences 83(3), 351-354 (2 figures). Czech Geological Survey, Prague. ISSN 1214-1119. Manuscript received January 30, 2008; accepted in revised form July 18, 2008; issued September 30, 2008.

Carlos Roberto A. Candeiro, Laboratório de Paleobiologia, Curso de Ciências Biológicas, Campus de Porto Nacional, Universidade Federal do Tocantins, Rua 03, Qd. 17, s/nș - Jd. dos Ipês, Zip Code 77500-000, Porto Nacional, Tocantins State, Brazil; candeiro@yahoo.com.br•Darren H. Tanke, Royal Tyrrell Museum of Palaeontology, Box 7500, Drumheller, Alberta, TOJ 0YO, Canada; darren.tanke@gov.ab.ca

Dinosaur teeth especially theropods have strong lateral carinae on their teeth. Split carinae have been reported in several theropod dinosaur families, observed on isolated teeth of predominantly North American taxa, including allosaurs, tyrannosaurs, and the maniraptoran Dromaeosaurus (Erickson 1995, Fiorillo \& Gangloff 2000; see Tanke \& Rothschild 2002 for literature review). The condition typically manifests as a faint to distinctive Y-shaped split of the proximal anterior serration row (Erickson 1995). Sereno \& Brusatte (2008) recently reported an isolated carcharodontosaurid tooth from the Aptian-Albian Elrhaz Formation of Niger with an anterior split carina.

Here we describe a carcharodontosaurid tooth from the collections of the Centro de Pesquisas Paleontológicas Llewellyn Ivor Price (CPP), Peirópolis, Uberaba, Minas Gerais, Brazil (Fig. 1). This specimen was collected from the late Maastrichtian Serra da Galga Member of the Marília Formation (Dias-Brito et al. 2001) and our identification constitutes the first report of a theropod tooth with a split carina from South America.

Terminology. - Teeth parameter terminology follows that of Currie et al. (1990) and Erickson (1995).
Measurement. - We used a Fowler-Sylvac caliper for measuring tooth parameters.

Institutional abbreviations. - CPP, Centro de Pesquisas Paleontologicas Llewllyn Ivor Price, Peiropolis, Uberaba, Minas Gerais, Brasil; TMP, Royal Tyrrell Museum of Palaeontology, Drumheller, Alberta, Canada.

Other abbreviations. - DSDI (Denticle Size Difference Index), FABL (Fore-Aft Basal Length), TCH (Tooth Crown Height).

\section{Description}

Tooth CPP 156 (Fig. 2A) is relatively small (25.59 mm), recurved posteriorly, and broadly oval in cross-section at its base (Fig. 2B), becoming more flattened towards the apex of the crown. CPP 156 can be identified as theropod tooth on the basis of size, shape and your denticles that are morphologically similar to those of Theropoda. This morphology indicates that the tooth is derived from the anterior region of the jaws, and perhaps is a premaxillary.

The specimen lacks a root but the preservation of the crown is good. Both carinae present large and expanded denticles, with posterior carina showing only the apical part of the denticles. Unworn denticles are chisel-shaped as in other theropods, e.g., Dromaeosauridae, Abelisauridae and Carcharodontosauridae (Currie et al. 1990, Candeiro 2002, Candeiro et al. 2004a). Blood grooves occur (Fig. 2C-E) between adjacent denticles extend onto the surface of the tooth. The DSDI varies between $0.95 \mathrm{~mm}$ and $1.08 \mathrm{~mm}$, with a mean value of $1.03 \mathrm{~mm}$.

The surface enamel of the cusp is smooth with wrinkled bands that are not present at the base of the denticles. The FABL is $14.28 \mathrm{~mm}$. The most prominent feature of the cusp is a well-developed split anterior carina arising from near the tip of the anterior tooth crown (Fig. 2C). The normal anterior carina row medial position (shown in Fig. 2D) extends along the entire tooth margin. The split (extra) carina row (Fig. 2E) is shorter $(24.73 \mathrm{~mm}$ ), and the serrations are a third smaller, but show the same morphology as those on the anterior and posterior carina. The split carina row arises from the $5^{\text {th }}$ denticle (counting away from the apex of the crown), splits and gently curves labi- 

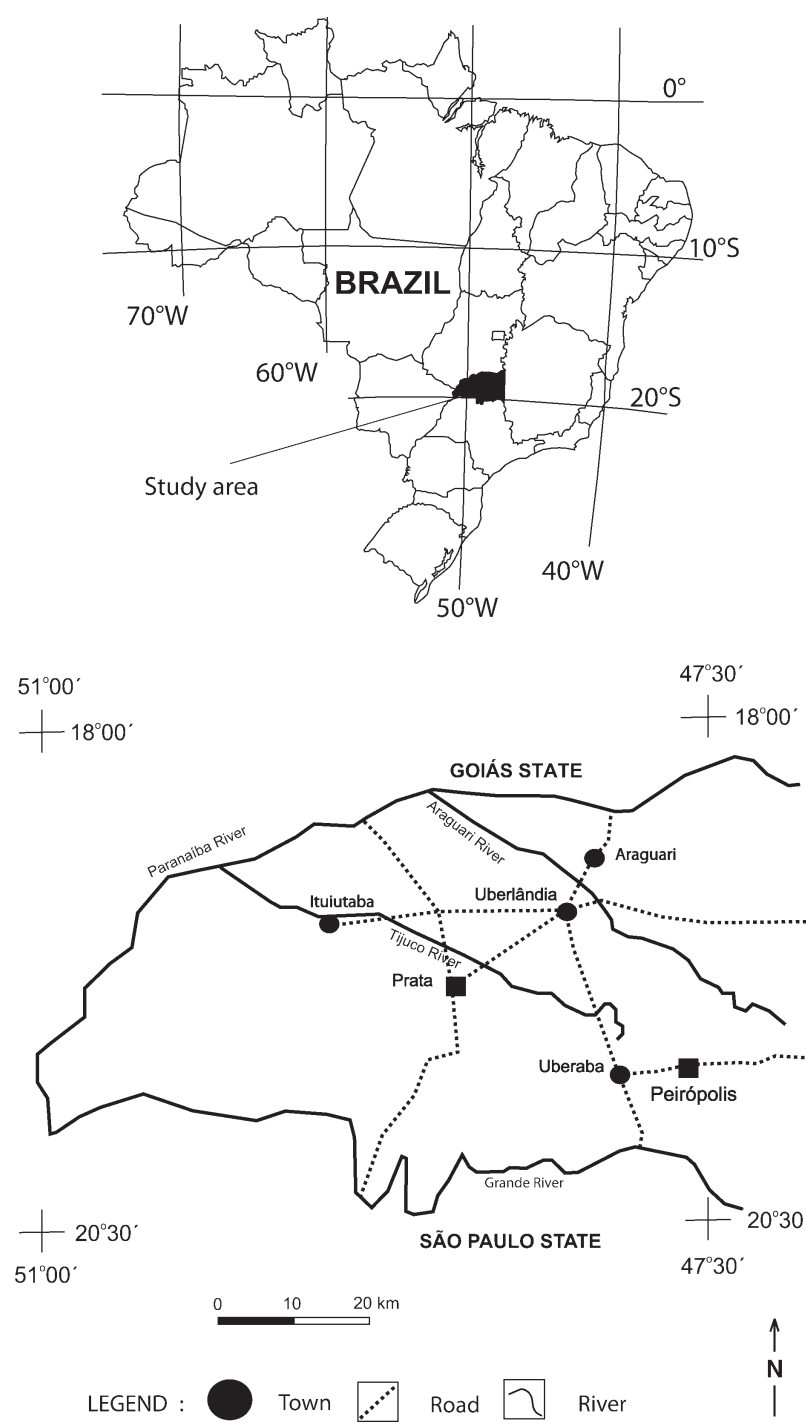

Figure 1. Map showing the Peirópolis locality, Minas Gerais, Brazil in the Marília Formation (Bauru Group, Upper Group) area.

ally from the main carina row forming an angle of approximately 45 degrees.

\section{Discussion}

Wrinkled enamel bands are typical of the teeth of Carcharodontosauridae, some Dromaeosaurus teeth from Alberta, Canada (TMP 98.68.111, TMP2000.57.78, TMP2002.60.11), some Tyrannosauridae (e.g., Albertosaurus sarcophagus, Tyrannosaurus), and a few other theropods of uncertain systematic position (Candeiro 2007, Candeiro et al. 2004a). CPP 156 shows a mosaic of features making taxonomic placement problematic; no diagnostic carcharodontosaurid jaws with teeth or body fossils are known from the assemblage that would help confirm the identity. Carcharodontosaurids have not previously been found from the Maastrichtian, but new information (Candeiro 2002, Veralli \& Calvo 2004, Candeiro et al. 2004a, b, Martinelli \& Forasepi 2004, Apesteguía et al. 2004) indicates younger occurrences for this group. Tooth CPP 156 differs from carcharodontosaurid teeth in the cross-sectional shape and relative size of the denticles (Candeiro 2002), but this may be a reflection of the anterior position of the tooth along the dental series. It also differs from abelisaur teeth in having less recurved crowns (Candeiro et al. 2004). CPP 156 shows similarities to these two groups in having a high DSDI similar to other carcharodontosaurid teeth (e.g., Giganotosaurus and Mapusaurus). Within carcharodontosaurids, CPP 156 is more similar to the Argentinean genus Giganotosaurus than to Carcharodontosaurus from North Africa, or even to carcharodontosaurid teeth from the São Luis Basin (Cenomanian, Maranhão, Brazil; Medeiros \& Schultz 2002) in that the mid to distal denticles are chisel-shaped rather than inclined apically.

Some large theropod teeth, referable to Tyrannosaurus, Daspletosaurus, Albertosaurus, Alectrosaurus, and Allosaurus also exhibit split carinae (Currie et al. 1990, Erickson 1995, Brochu 2003). Erickson (1995) pointed out that the occurrence of split carinae in tyrannosaurids can be attributed to multigenetic derivation, meaning that the Brazilian carcharodontosaurid tooth was possibly affected by genetic derivation which produced a morphological control in the dentition that acted locally in developing on the CPP 156. The same feature is also found in the teeth of other Laurasian theropods (Farlow et al. 1991). To explain the Brazilian example, we consider that Gondwanan theropods had the same multigenetic derivation feature as their Laurasian counterparts.

Erickson (1995) found that 114 of 993 (11.4\%) of North American tyrannosaurid teeth exhibited split carinae. By comparison our finding is comparatively low as there is so far only one CPP carcharodontosaurid tooth out of $108(0.9 \%)$ affected. This difference, however, surely reflects the smaller size of the Brazilian sample or might relate to other factors, such as large regional variations (Erickson 1995, table 1).

The distally-positioned split carina on CPP 156 equates well with other similar but rare examples in North American tyrannosaur specimens (i.e. TMP94.143.1 Daspletosaurus premaxillary tooth). The Brazilian discovery fulfills predictions rather than suggests a common character with other theropods. For example, the split carina pathology was predicted to be present throughout the Theropoda, besides the several tyrannosaurid taxa (Currie et al. 1990, Erickson 1995). Because a split in the carina usually affects the more proximal region, the Albertan and Brazilian specimens noted here with a more distal condition can be considered a rare occurrence and perhaps no more than a variation. 

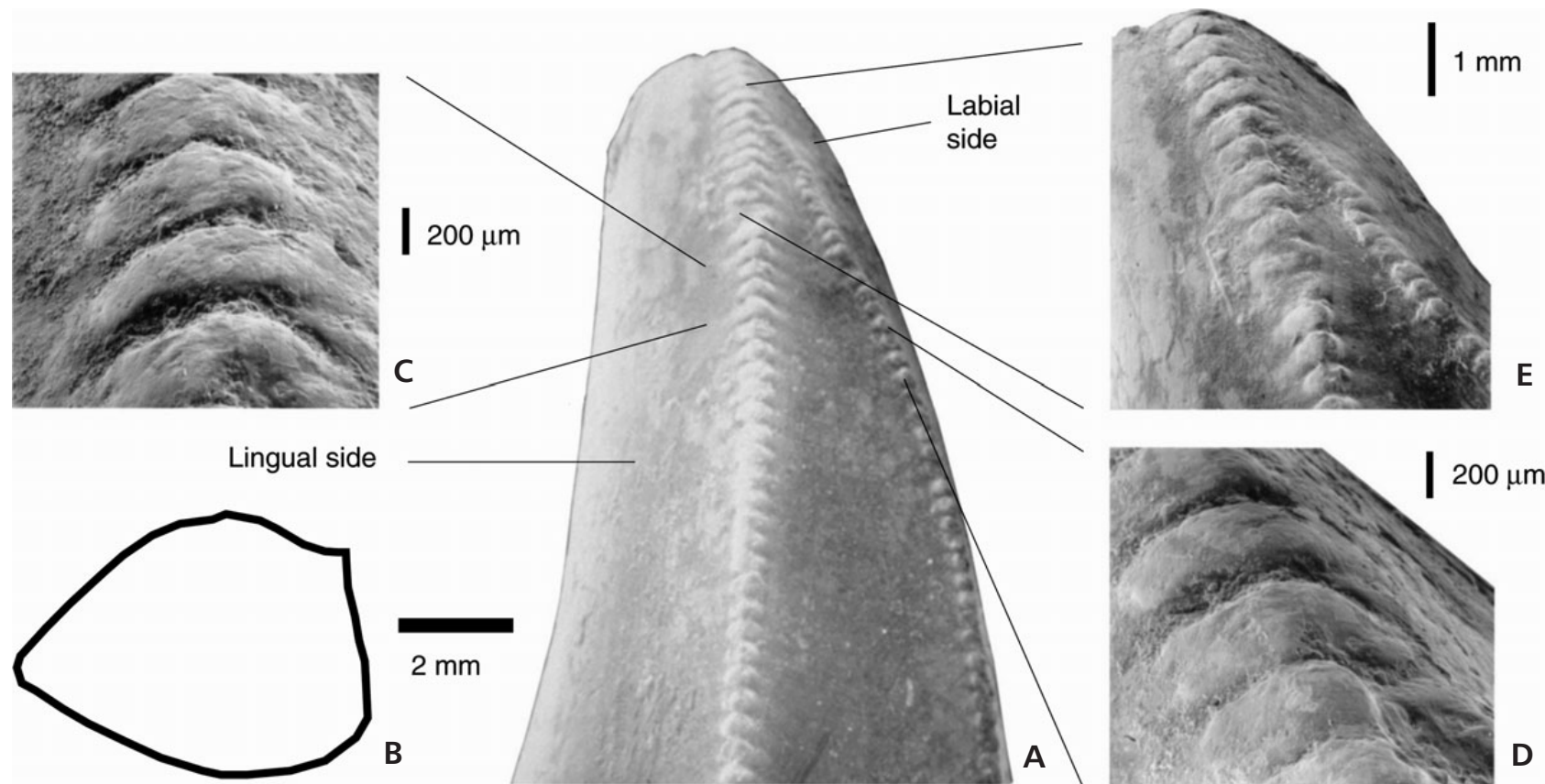

Figure 2. Carcharodontosaurid tooth (CPP 156) from the Serra da Galga Member, Marília Formation, Minas Gerais, Brazil. • A - entire specimen. - B - basal cross-sectional tooth. $\bullet \mathrm{C}$ - detail of denticles in the normal anterior carina. $\bullet \mathrm{D}$ - detail of anterior denticles in the extra carina. $\bullet$ E - detail of anterior denticles of the split carina.

\section{Acknowledgements}

This paper is based on R.C.'s M.Sc. Dissertation from the Departamento de Geologia, Universidade Federal do Rio de Janeiro under advisors L.P. Bergqvist (Universidade Federal do Rio de Janeiro) and F. Novas (Museo Argentino de Ciencias Naturales). We are grateful to L.B. Ribeiro (Peirópolis, Uberaba, Brazil) and Jim Gardner (Collections, Royal Tyrrell Museum), who provided access or extended loans of specimens in their care. Rogério Martins (Petrobrás, Rio de Janeiro, Brazil) took the scanning electron microphotographs. We would like to thank Gregory Erickson (Florida University) and Sheila R. Porta (Universidade Federal de Uberlândia) for many helpful comments in the early version of this work. Patty Ralrick (University of Calgary) and Susan Turner (Brisbane) edited the manuscript. Funding for this study was provided in part by a Capes Fellowship and Jurassic Foundation grants to the first author.

\section{References}

Apesteguía, S., CAndeiro, C.R.A. \& Agnolin, F.L. 2004. Late Cretaceous dwarf carcharodontosaurids in Patagonia. Ameghiniana 41(4), supplement, 35R.

BROCHU, C.A. 2003. Osteology of Tyrannosaurus rex: insights from a nearly complete skeleton and high-resolution computed tomographic analysis of the skull. Journal of Vertebrate Paleontology, Memoir 7, 1-138.

CANDEIRO, C.R.A. 2002. Dentes de Theropoda da Formação Marília (Santoniano-Maastrichtiano), Bacia Bauru, região de Peirópolis, Minas Gerais, Brasil. 126 pp. Master dissertation,
Programa de Pós-Graduação em Geologia, Universidade Federal do Rio de Janeiro.

CANDEIRO, C.R.A. 2007. Padrões morfológicos dos dentes de Abelisauroidea e Carcharodotnosauridae (Theropoda, Dinosauria) do Cretáceo da América do Sul. 208 pp. Doctor thesis, Programa de Pós-Graduação em Geologia, Universidade Federal do Rio de Janeiro.

CAndeIro, C.R.A., Abranches, C.T., Abrantes, E.A., AVILlA, L.S., MARTINS, V.C., MOREIRA, A.L., TORRES, S.R. \& BERGQVIST, L.P. 2004a. Dinosaur remains from São Paulo State, Brazil (Bauru Basin, Adamantina Formation, Upper Cretaceous). Journal of South American Earth Sciences 18, 1-10. DOI 10.1016/j.jsames.2004.08.004

CANDEIRO, C., BergQvist, L., Novas, F. \& CURRIE, P. 2004b. Theropod teeth from the Marília Formation (Upper Maastrichtian), Minas Gerais State, Brazil. Journal of Vertebrate Paleontology 24(3), supplement, 43A.

CURRIE, P.J., RIGBY, J.K. \& SLOAN, R.E. 1990. Theropod teeth from the Judith River Formation of southern Alberta, Canada, 107-125. In CARPENTER, K. \& CURRIE, P.J. (eds) Dinosaur Systematics, Approaches and Perspectives. Cambridge University Press, Cambridge.

DiAs-Brito, D., MusacChIO, E.A., CASTRO, J.C., MARANHÃO, M.S.A., SUÁREZ, J.M. \& RODRIGUES, R. 2001. Grupo Bauru: uma unidade continental do Cretáceo do Brasil - concepções baseadas em dados micropaleontológicos, isotópicos e estratigráficos. Revue de Paléobiologie 20, 245-304.

ERICKSON, G.M. 1995. Split carinae on tyrannosaurid teeth and implications of their development. Journal of Vertebrate Paleontology 15, 268-274. 
FARlow, J.O., BrinKman, D.L., ABleR, W.L. \& CURRIE, P.J. 1991. Size, shape and serration density of theropod dinosaur lateral teeth. Modern Geology 16, 161-198.

FIORILLO, A.R. \& GANGLOFF, R.A. 2000. Theropod teeth from the Prince Creek Formation (Cretaceous) of northern Alaska, with speculations on arctic dinosaur paleoecology. Journal of Vertebrate Paleontology 20, 675-682.

DOI 10.1671/0272-4634(2000)020[0675:TTFTPC]2.0.CO;2

Martinelli, A.G. \& ForASEPI, A.M. 2004. Late Cretaceous vertebrates from Bajo de Santa Rosa (Allen Formation), Río Negro Province, Patagonia (Argentina) with description of a new sauropod (Titanosauridae) dinosaur. Revista del Museo Argentino Ciencias Naturales "Bernardino Rivadavia” 6(2), 257-305.
Medeiros, M.A. \& Schultz, C.L. 2002. A fauna dinosauriana da "Laje do coringa", Cretáceo Médio do Nordeste do Brasil. Arquivos do Museu Nacional 60(3), 155-162.

SERENO, P.C. \& BRUSATTE, S.L. 2008. Basal abelisaurid and carcharodontosaurid theropods from the Lower Cretaceous Elrhaz Formation of Niger. Acta Paleontologica Polonica 53(1), 15-46.

TANKE, D.H. \& ROTHSCHILD, B.M. 2002. DINOSORES: An Annotated Bibliography of Dinosaur Paleopathology and Related Topics - 1838-2001. New Mexico Museum of Natural History and Science Bulletin 20(1), 1-96.

VerALLI, C. \& CALVO, J.O. 2004. Dientes de terópodos carcharodontosáuridos del Turoniano superior-Coniaciano inferior del Neuquén, Patagonia, Argentina. Ameghiniana 41(4), 587-590. 